AUDIT

\title{
Do post-take ward round proformas improve communication and influence quality of patient care?
}

\author{
A G Thompson, K Jacob, J Fulton, C R McGavin
}

See end of article for

authors' affiliations

Postgrad Med J 2004;80:675-676. doi: 10.1136/pgmi.2003.016097

....................

Correspondence to:

Dr Andrew Thompson,

Derriford Hospital,

Derriford Road, Plymouth

PL6 8DH, UK; andrew.

thompson2@phnt.swest.

nhs.uk

\begin{abstract}
The post-take ward round is a critical time for reviewing the initial history, examination and results, and the stage at which further treatment and investigations will be determined. However documentation of this ward round is often inadequate, so the benefits of decision making are lost. The documentation of 95 ward rounds was assessed for key items of information before and after the introduction of a proforma sheet. The introduction of the proforma led to a significant improvement in the documentation of a diagnosis, management plan, prophylaxis for deep vein thrombosis, and resuscitation status $(p<0.05)$, which will
\end{abstract}

Submitted

6 November 2003

Accepted

10 December $2003 \quad \begin{aligned} & \text { management plan, prophylaxis for deep } \\ & \text { have a significant impact on patient care. }\end{aligned}$

Q uality of patient care is reliant on the quality of information communicated between health care professionals. With new patterns of working (partial and full shift patterns) and ward based management systems, a patient's admission to hospital may involve several doctors and geographic moves. Each phase shift may distort or lose information that is crucial for patient care and so the clinical risk escalates, in a proportion dependent on the number of changes. The management of this risk, and consequently the quality and safety of patient care, depends on clear documentation.

Guidelines suggest that a consultant must conduct a posttake ward round (PTWR) and review every patient within 24 hours of admission to hospital. ${ }^{1}$ The history and initial results are reviewed, clinical decisions are made, a management plan is formulated, and further investigations planned. The PTWR is the prime opportunity for documentation, however it can be a pressurised and chaotic time, and hence the quality of documentation may be affected. Fernando et al found that junior doctors on a surgical ward round failed to document the consultants' clinical findings and management decisions. Information given to patients by consultants regarding clinical findings and treatment planned was recorded in a median of $6 \%$ of consultations. ${ }^{2}$ The value of ward rounds are reduced if decisions are not made, not recorded, and/or illegible handwriting leads to the loss of information to subsequent clinicians. Additionally, there are certain decisions that are of crucial importance to patient care, which the consultant should make, for example, resuscitation decisions, which are often ducked or ignored. ${ }^{3}$

This study assessed the adequacy of documentation at the PTWR and the impact of introducing a one page proforma on documentation.

\section{METHODS}

Over a three week period, 100 clinical records were examined. The quality of the PTWR documentation was assessed for key items of information. These were the patient's name and hospital number; the name of the doctor documenting the information; the consultant's name; patient's blood, electrocardiography and radiography results; the consultant's diagnosis/problem list; management plan (with an indication whether investigations had been organised or just advised); deep vein thrombosis prophylaxis; and resuscitation status.

After the study a proforma was developed and distributed (see fig 1). Doctors were encouraged to use the proforma on the PTWR, although they were unaware of the study or the reason for the sheet. After the proforma was used for two months, the audit was repeated, examining records over three weeks. Results were compared by $\chi^{2}$ analysis, with a Yates's correction on a Microsoft Excel program. Comparisons with $\mathrm{p} \leqslant 0.05$ were considered statistically significant.

\section{RESULTS}

One hundred clinical records were examined, of which 95 had a documented PTWR. After the proforma sheet was introduced 95 clinical records were reviewed. The results are shown in table 1.

\section{DISCUSSION}

A significant improvement in documentation was seen. Specific improvements included the consultant's diagnosis $(\mathrm{p}<0.01)$, the management plan $(\mathrm{p}=0.01)$, and the admitting doctor's name $(p<0.01)$. The clear identification of a diagnosis and a management plan means that subsequent doctors can initiate treatment as soon as they take over the care, rather than repeating the initial examination and discussion of the PTWR. They also have the opportunity to identify and communicate with the admitting doctor to obtain clarification of the notes. No difference was observed in the documentation of results such as bloods, chest radiography or electrocardiography, some of which may not be available at the time of the PTWR and therefore would not be influenced by the proforma introduction. A significant improvement was noted in documentation of deep vein thrombosis prophylaxis and resuscitation status, although the actual numbers completing this section on the proforma remains disappointing.

Most doctors, when questioned about the proforma, found it straightforward and user-friendly. It was regarded as useful to clinical practice and completion compliance was enhanced by its inclusion in the patient admission pack. Other health 


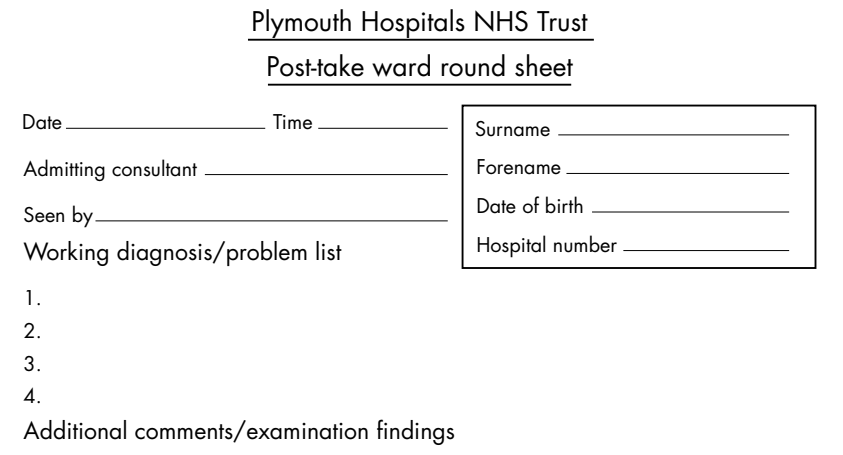

Investigations

$\begin{array}{lllll}\mathrm{NA} & \text { Gluc } & \mathrm{PO}_{4} & \text { WCC } & \text { ECG } \\ \mathrm{K} & \mathrm{Chol} & \mathrm{AlP} & \mathrm{Hb} & \\ \mathrm{HCO}_{3} & \mathrm{~T} \text { Prot } & \mathrm{Bil} & \text { Plts } & \\ \text { Urea } & \mathrm{Alb} & \mathrm{AST} & \text { MCV } & \text { CXR } \\ \text { Creat } & \mathrm{Ca} & \mathrm{CK} & \text { INR } & \end{array}$

Management plan (please tick in the box if done)

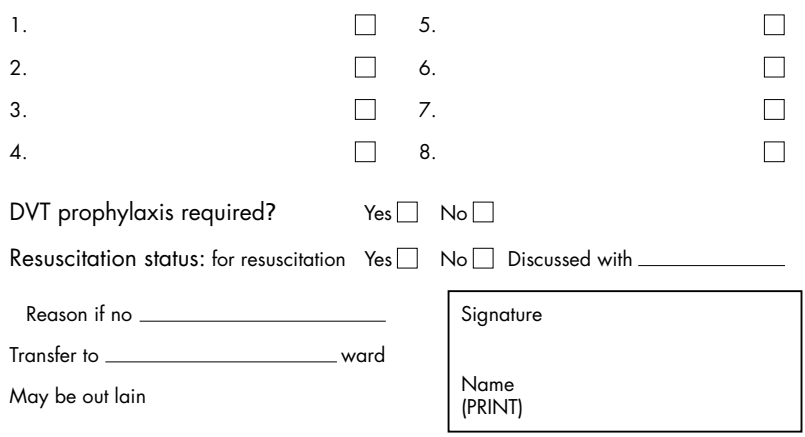

Figure 1 Proforma sheet.

professionals, especially nurses, found it a useful reference document when they received a new patient to the ward.

Although simple in principle, maintaining good standards of clinical documentation remains a problem, despite the importance stressed by professional bodies and defence organisations. The General Medical Council guidelines for good clinical care includes the following statement "keep clear, accurate, legible and contemporaneous patient records" ${ }^{4}$ The first three of the Medical Defence Union's 10
Table 1 Documentation of key items of information before and after introduction of proforma

\begin{tabular}{llcc}
\hline & $\begin{array}{l}\text { No proforma Proforma used } \\
\text { (n=95; \%) }\end{array}$ & (n=95; \%) & p Value for $\chi^{\mathbf{2}}$ \\
\hline Patient's name & 99 & 100 & 1.00 \\
Hospital number & 92 & 81 & 0.06 \\
Consultant's name & 98 & 98 & 0.61 \\
SHO's name & 47 & 81 & $<0.01^{*}$ \\
Diagnosis & 56 & 96 & $<0.01^{*}$ \\
Management plan & 89 & 99 & $0.01^{*}$ \\
Chest $x$ ray & 45 & 47 & 0.88 \\
Bloods & 79 & 85 & 0.34 \\
ECG & 49 & 57 & 0.38 \\
DVT prophylaxis & 5 & 24 & $<0.01^{*}$ \\
Resuscitation status & 3 & 35 & $<0.01^{*}$ \\
\hline \\
DVT, deep vein thrombosis; ECG, electrocardiogram; SHO, senior house \\
officer.
\end{tabular}

Commandments of record keeping are (1) write legibly, (2) include the date and time, (3) sign thy name. ${ }^{5}$

In order to improve documentation, structured documents or proformas have successfully been introduced in acute asthma management in accident and emergency ${ }^{6}$ and pathology reporting. ${ }^{7}$

This study confirms the benefits of a proforma for the PTWR and demonstrates the improvement in documentation of key items when included on such charts.

\section{Authors' affiliations}

A G Thompson, K Jacob, J Fulton, C R McGavin, Derriford Hospital, Plymouth, UK

\section{REFERENCES}

1 Federation Of Royal Colleges of Physicians of the UK. Acute medicine: the physician's role. Proposals for the future. London: RCP, 2000.

2 Fernando KJ, Siriwardena AK. Standards of documentation of the surgeonpatient consultation in current surgical practice. Br J Surg 2001;88:309-1.

3 A joint statement from the British Medical Association, the Resuscitation Council (UK) and the Royal College of Nursing. Decisions relating to cardiopulmonary resuscitation. London: BMA, 2002.

4 General Medical Council. Good medical practice. London: GMC, 1998.

5 Norwell N. The ten commandments of record keeping. Journal of the Medical Defence Union 1997;13:8-9.

6 Robinson SM, Harrison BDW, Lambert MA. Effect of a preprinted form on the management of acute asthma in an accident and emergency department. $J$ Accid Emerg Med 1996;13:93-7.

7 Rigby K, Brown SR, Lakin G, et al. The use of a proforma improves colorectal cancer pathology reporting. Ann R Coll Surg Engl 2002;84:290. 